\title{
A Dança de Salão como um dos conteúdos de dança na escola
}

\author{
Catia Mary Volp \\ Instituto de Biociências. UNESP - Univ Estadual Paulista, Campus de Rio Claro, \\ Departamento de Educação Física, Rio Claro, SP, Brasil
}

\begin{abstract}
Resumo: Este trabalho trata do direito de todo cidadão à dança. Focaliza as orientações oficiais que tratam a dança como conteúdo legítimo na escola discutindo brevemente a dificuldade de efetivação deste conteúdo. Dentre as várias manifestações de dança destaca as Danças de Salão, suas características e benefícios. Traça o percurso histórico da Dança de Salão no Brasil nas instituições de ensino superior.
\end{abstract}

Palavras-chave: Dança criativa. Dança de salão. Formação de professores.

\section{Ballroom Dance as one of the dance contents at school}

\begin{abstract}
This paper presents the right all citizens have to dance. It focus on the official orientations which deals with dance as a legitimate content at school briefly discussing the difficulty to implement this content. Among various dance manifestations we highlight Ballroom Dance, its characteristics and benefits. We trace the historical path of Ballroom Dance in Brazil at colleges.
\end{abstract}

Key Words: Ballroom dances. Creative dance. Professional development.

\section{Introdução}

Estamos assistindo a algumas tentativas de mudanças na sociedade ora retomando antigos valores, ora inovando de fato em função daquilo que perplexos identificamos como o que não queremos e onde, perplexos, nos damos conta que os comportamentos vigentes não são mais adequados. A velocidade com que a tecnologia avança trazendo cada vez mais comodidades tem seu preço maior estampado nas desigualdades sociais e no conjunto de valores da sociedade. $\mathrm{Na}$ contramão das conseqüências nefastas proclamam-se códigos de direitos, prega-se cidadania e respeito e luta-se para um processo educacional eficiente cuja inércia é mais forte que todos ideais.

O panorama real é desalentador, mas se um dos aspectos motivadores da ação é o desafio "tomemos o boi pelos chifres" e cientes de nosso papel tentemos colaborar para a mudança desta realidade.

\section{Dança na Escola: do direito às oportunidades}

Em 1948, em decorrência das grandes guerras e suas conseqüências, a Organização das Nações Unidas aprovou a Declaração dos Direitos Humanos cujos princípios básicos são a liberdade, a igualdade e a fraternidade. Se analisarmos as diferenças nestes valores daquela época com o que vemos hoje podemos dizer que houveram mudanças significativas, mas estamos longe do ideal e caminhando em passos muito lentos.

Dentre os direitos promulgados na Declaração quero salientar o direito à educação e o direito à cultura. No aspecto educacional quero enfatizar não só o direito à instrução gratuita e ao acesso a ela, mas todo o processo institucionalizado ou não que engloba a cultura própria bem como o conhecimento de outras, a liberdade de expressão através de todas e quaisquer linguagens, o acesso às produções humanas em todos os campos de conhecimento erudito ou não.

No Brasil ainda tivemos, em 1990, a aprovação do Estatuto da Criança e do Adolescente onde encontramos capítulos que tratam "Do Direito à Educação, à Cultura, ao Esporte e ao Lazer" e "Da Informação, Cultura, Lazer, Esportes, Diversões e Espetáculos", capítulos estes destacados pelo que pretendemos encadear no decorrer deste artigo.

No sistema educacional brasileiro vigente as diretrizes são apresentadas pelos Parâmetros Curriculares Nacionais (PCNs). Referindo-se resumidamente aos objetivos propostos para 0 Ensino Fundamental, muitos dos direitos expostos acima parecem estar presentes, ou seja, a compreensão da cidadania como um agir em sociedade com liberdade, igualdade $e$ fraternidade, respeitando as diferentes identidades e comunicando-se para chegar a decisões coletivas, entendendo e mantendo a cultura própria e as outras culturas sem 
discriminação, percebendo-se como integrante, dependente e agente transformador do ambiente, bem como agente responsável de si em todas as esferas da vida e sempre em busca de qualidade de vida, usuário, produtor e apreciador das diferentes linguagens e tecnologias visando o bem comum. (Brasil, 1997, 1998)

Os Parâmetros Curriculares Nacionais do Ensino Médio (PCNEM, Brasil, 2000), na área de Linguagens, Códigos e suas Tecnologias explicitam como objetivos o desenvolvimento do jovem como conhecedor das linguagens que lhe permitam comunicar, expressar suas idéias, reconhecer diferentes produtos de linguagens, interpretá-las, interpretando a realidade (textos e contextos nos quais se inserem), respeitando as diferentes manifestações de linguagens provenientes de diferentes grupos sociais, colocando-se como apreciador, produtor e usuário das linguagens, aplicando os conhecimentos nas diferentes instâncias da vida.

Em função destas considerações posso acrescentar que todo cidadão tem "direito à dança" como promulga a daCi (dance and the Child international). Note-se que a sigla mantém apenas o "C" de "Child" em letra maiúscula com a intenção explícita de demonstrar o ente mais importante desta organização internacional sem fins lucrativos.

Este direito se baseia no entendimento do que vem a ser a "dança", esta manifestação genuinamente humana, cuja origem remonta ao início da vida humana, com função provável de comunicação, deixando sem esclarecimento até hoje o que deve ter surgido primeiro: a linguagem falada ou a dança, a marcação rítmica na dança ou a música. Sua evolução nos traz, nos dias de hoje, uma gama imensa de manifestações dançantes, com funções das mais variadas e com inserções diferenciadas na vida das pessoas. Juntamente com a evolução técnica na dança veio o ícone ( $\mathrm{da}(\mathrm{o})$ bailarina(o)) e os preconceitos que aos poucos foram distanciando o homem desta sua manifestação natural. Por isso temos hoje a necessidade de enfatizar o direito que todos temos à dança.

Analisemos um pouco os principais objetivos da daCi, que como foi apresentado prioriza a criança e o jovem em todos seus processos, e que são:

- promover oportunidades em todo o mundo para que crianças e jovens (0-18) possam experimentar a dança como criadores, intérpretes e espectadores;
- assegurar que os interesses de crianças e jovens relacionados com a dança sejam respeitados e desenvolvidos;

- encorajar pesquisas na área de dança para crianças e jovens;

- assegurar que a dança seja incluída no currículo escolar e em programas comunitários;

- promover intercâmbio de idéias e programas escolares e comunitários na área de dança para crianças, jovens e profissionais a eles relacionados. (daCi Brasil, 2008)

Estes objetivos parecem simples e podem ser compartilhados por todas organizações sociais. $O$ lugar da dança está "garantido" pela lei e suas diretrizes no sistema educacional nacional no ensino fundamental e médio, entretanto sua implementação ainda não pode ser considerada realidade.

Quais são os reais entraves para a efetiva implementação? Se voltarmos o olhar para a escola, principalmente a escola pública, o quadro será complexo, confuso e nosso esforço em determinar prioridades, ações conjuntas, responsabilidades compartilhadas, será enorme. Não pretendo aqui discorrer sobre todos os fatores da escola, mas não posso "fazer de conta" que eles não existem. Enfatizo que as ações devem ser conjuntas envolvendo toda a comunidade escolar e que todos devem se responsabilizar pelas ações e suas conseqüências se é que querem bons resultados. Ações isoladas além de exaurir com as forças do implementador sofrerão resistências que pouco acrescentarão positivamente ao resultado final.

Concordando com Marques (1997), a sociedade hoje, extremamente tecnológica, se manifesta com valores e comportamentos diversos de duas décadas atrás (quanto mais de um século). A velocidade das informações, da inserção de novas tecnologias no mercado é muito grande e diverge do ritmo biológico que tenta se adaptar (mas ainda não sabemos as reais conseqüências disso). Entretanto, a escola ainda mantém procedimentos e valores tradicionais que pouco dialogam com a realidade. Marques (1997) enfatiza que a escola negligencia o corpo, a arte, e eu acrescento que nela não há lugar para as emoções. E estes são apenas três aspectos de um universo.

Retomando nosso tema, para que a dança seja implementada de fato na escola precisamos profissionais que possam atuar efetivamente e do reconhecimento da comunidade escolar da dança como inerente ao ser humano. Isso nos remete a dois questionamentos: de que dança estamos tratando e que formação profissional necessitamos. 
A dança é uma manifestação humana comum a todas as culturas em todos os tempos. Basta observarmos algumas destas manifestações para nos darmos conta da riqueza das informações que elas transmitem sobre suas culturas de origem, sobre os aspectos primordiais da época em que foram criadas, sobre os atores que delas participam, enfim, como elas "falam" e "retratam" homens, mulheres, crianças, seus grupos e interações entre si e com experiências vividas. Esta dança faz parte da vida do cidadão?

Como tal, valorizando sua essência, talvez não. Se sairmos questionando a todos, muitos responderão que a dança não faz parte da sua vida esquecendo-se do samba rock da tarde de churrasco no quintal de casa, por exemplo. Por que? Porque hoje vigora o senso comum de que dança é aquela do espetáculo cujo ator passou e passa por rigoroso treinamento técnico, mundo de poucos, daquele que a natureza já gratificou com corpo próprio para a dança (outro ledo engano). E há o mundo das "dancinhas", também espetáculo, veiculadas pela mídia, que também exigem atores com qualidades especiais inigualáveis aos cidadãos não atores. O que ele dança na tarde de churrasco? Ah! É brincadeira, só para passar o tempo.

Mas esta "brincadeira" é séria, dela decorrem mensagens que alimentam o conhecimento de si, do outro, que podem servir de instrumento de conquista, que podem favorecer o equilíbrio de tensões psicológicas e musculares, enfim, manifestação humana repleta de vida.

O que isto nos deve fazer pensar é que a manifestação dançante do ser humano deve entrar na escola pela porta da frente, sem preconceitos, sem primazia de técnicas tradicionais, conhecimento de artes eruditas em detrimento das manifestações populares tão ricas quanto, tão portadoras de conhecimento quanto, tão propiciadoras do saber quanto aquelas. A classificação das danças em eruditas e populares deveria ser apenas didática e não efetivação de dominância de classes e perpetuação de preconceitos.

Qual deveria ser a formação dos profissionais educadores em dança para atuarem nas escolas? Uma formação tão educacional quanto o que se espera de sua atuação e tão próxima à realidade social e diversificada quanto a realidade escolar. A dança é conteúdo tanto da Arte quanto da Educação Física segundo os PCNs (1997, 1998) e PCNEM (2000). Os cursos superiores de Dança e de Educação Física devem formar seus alunos numa proposta triangular (Ana Mae Barbosa, 1997), em outras palavras respeitando as dimensões conceituais, procedimentais e atitudinais do conhecimento em dança como manifestação humana (ampla). O ensino no nível superior também deve ser sintético-sistêmicocorporal-intuitivo, nos termos de Marques (1997), levando o corpo e as emoções para as situações de aprendizagem, considerando tanto aspectos científicos, quanto pedagógicos, quanto artísticos da área.

Em qualquer instância, em qualquer nível ou instituição a dança deve levar ao conhecimento de si, da integridade e singularidade de cada um, da complexidade e da simplicidade de viver, pensar, sentir movimento. A dança tem esta potencialidade.

Cabe neste momento nos referirmos às palavras de Helena Katz, crítica de dança, que afirma que a dança é o pensamento do corpo (1994). Os estudos de Damásio (2000) têm contribuído muito para mudar a concepção dualista (corpo e mente) e reconhecer a conexão entre emoção e consciência e entre emoção, consciência e corpo. Mauro Muszkat, neurologista da Unifesp, descreve que durante a dança há maior ativação das áreas associativas do cérebro, que integram as funções motoras e de sensibilidade e dão significado a cada ação (CHARÃO, 2002). Conseqüentemente, a dança serve para ampliar a capacidade sensorial e de compreensão do mundo e, paralelamente, aumenta o repertório de comunicação do indivíduo.

As manifestações de dança são inúmeras e não há como inserir todas no calendário escolar. O professor terá que fazer escolhas e dar significado aos conteúdos propostos. A consideração dos textos e contextos da comunidade é o primeiro acervo a ser considerado e a partir daí a construção de todo o programa é mera conseqüência.

\section{Dança de Salão como um dos conteúdos de dança na escola}

Uma das manifestações de dança que elejo como altamente aconselhável na escola é a Dança de Salão. E pelo tempo que venho trabalhando com esta modalidade sinto-me na obrigação de partilhar meus conhecimentos com todos. Embora pareça mais adequada para jovens do ensino médio, experiências nos mostram que ela é bastante efetiva no ensino fundamental também.

Mas o que vem a ser a Dança de Salão? È aquela dançada aos pares, em contato, que desenvolvem estruturas de passos variados no salão harmonizando-os em relação à parceria e à 
música e deslocando-se no sentido anti-horário. É normalmente praticada em reuniões sociais das mais diversas e pode ou não ter um aspecto técnico associado ao seu desempenho (Volp, 1994).

A movimentação característica na Dança de Salão é o andar, suas variações e giros. O ensino da Dança de Salão envolve técnica de postura (para que cada um possa carregar o seu próprio corpo e organizar-se em função do outro); de execução de passos (cada ritmo tem suas próprias características expostas nos passos); de conduzir e ser conduzida (para que a sensibilidade e a percepção dos próprios movimentos e dos movimentos do outro possa ser compreendida); percepção rítmica (para que os movimentos possam harmonizar-se à música) (Volp, 1994); história de cada ritmo e sua evolução (para análise da cultura de origem); apreciação de danças (para desenvolver apreciação e criticidade); etiqueta de salão (conjunto de comportamentos éticos com 0 objetivo de permitir que todos dancem num salão); criação em dança (oportunidades para criação de passos e deslocamentos).

A Dança de Salão agrega o convívio social à sua prática que pode servir de instrumento para ações cooperativas nas mãos do professor.

As relações interpessoais são muito trabalhadas na dança de salão e, através delas, as intrapessoais. A solução dos problemas motores na situação aos pares, seguindo um determinado ritmo musical e uma trajetória num salão que deve ser respeitosamente compartilhada com outros, coloca os executantes em situações ímpares de enfrentamento consigo mesmo e com seus parceiros(as).

Algumas experiências acerca da Dança de Salão na escola são retratadas em filmes, embora na cultura americana, mas que ilustram bem o rico ambiente de ensino e aprendizagem deste conteúdo. Um deles, protagonizado por Antonio Bandeiras intitulou-se "Vem Dançar", e conta a história do professor Pierre Dulaine, que iniciou o programa popular que levou a dança de salão às escolas públicas de Nova York. O outro, um pouco anterior, intitulou-se " Vamos Todos Dançar" (Mad Hot Ballroom, 2005) e trata-se de um documentário onde Marilyn Agrelo retrata a inclusão através da dança de salão nas escolas públicas. Como documentário, ele traz depoimentos das crianças e jovens participantes que são valiosíssimos.

Em termos acadêmicos posso citar minha intervenção com alunos de $5^{\circ}$ ano e de $9^{\circ}$ ano em escola particular no interior de São Paulo. A segunda intervenção resultou em minha tese de doutorado (Volp, 1994). Ambas foram muito significativas e alguns aspectos foram interessantes e vou destacar. Para o $5^{\circ}$ ano pensei em ritmos alegres, rápidos, como rock e cha-cha-chá e quando abri a opção para que eles pudessem escolher fiquei surpresa, pois a escolha unânime foi para o tango. Para o $9^{\circ}$ ano pudemos ampliar o leque de ritmos estudados e tanto os mais rápidos quanto os mais lentos foram bem aceitos com interesses diferentes. 0 maior desafio foi vencer a timidez dos rapazes, principalmente para convidar a dama para dançar. Isso nos levou a refletir sobre a importância das etiquetas (e respeito) e sua aplicabilidade nesta faixa etária. Rapazes e garotas necessitam deste conteúdo e de ambiente onde possam praticá-lo, excluindo-se os momentos de convívio espontâneo com "sua turma" cujos códigos comportamentais estabelecidos normalmente não permitem tais práticas.

Como experiência no ensino superior podemos relatar o programa de Dança de Salão instituído em 1984 pela Profa. Dra. Hildegard E. D. Krause e por mim na Universidade Federal de Viçosa, em Minas Gerais.

$\mathrm{Na}$ época, o Decreto 69.540 de $1^{\circ}$ de novembro de 1971 determinava a obrigatoriedade da educação física no ensino de $1^{\circ}, 2^{\circ}$ e $3^{\circ}$ graus. Para $03^{\circ}$ grau, segundo o documento, a educação física devia ter por objetivos dar continuidade aos conhecimentos adquiridos no $2^{\circ}$ grau, e a operacionalização dos objetivos ficava a cargo das instituições de ensino superior segundo suas possibilidades e através do oferecimento de diferentes modalidades.

$\mathrm{Na}$ Universidade Federal de Viçosa, na época, as modalidades oferecidas decorriam dos desportos e os alunos escolhiam a modalidade de sua preferência ou as que mais se aproximavam de sua preferência e disponibilidade. Mas a influência negativa das experiências anteriores e a desmotivação para a prática eram constantes e desalentadoras para todos os envolvidos.

Diante do quadro conflitante e tendo como referência experiências estrangeiras bem sucedidas de atividades não tradicionais mescladas às tradicionais, propusemos a Dança de Salão como modalidade. A administração estranhou a sugestão e aprovou a abertura, apenas de uma turma, num curso de extensão. A experiência foi tão significativa que, no ano seguinte a modalidade foi incluída no conjunto das oferecidas formal e regularmente para a 
exigência da educação física no $3^{\circ}$ grau sob a denominação "Educação Física Desportiva e Recreativa - Dança de Salão l". Este foi o primeiro curso de dança de salão no Brasil formalmente desenvolvido no programa de uma instituição de ensino superior oficial.

Os cursos de dança de salão existentes, então, estavam vinculados a entidades privadas não relacionadas ao ensino formal. Na maioria, estes cursos eram ministrados para um casal ou um indivíduo por aula. A dança de salão, na época, não estava em voga e a influência nordestina com seus forrós e lambadas ainda não tinha se instaurado.

$\mathrm{Na}$ proposta da dança de salão para universitários, portanto, estávamos na contramão da moda e a metodologia de ensino fugia aos exemplos em vigor. As aulas eram ministradas a grupos de 20 a 30 casais ao mesmo tempo. As professoras conduziam as aulas de forma coordenada para poder passar as informações das funções de cavalheiros, bem como de damas, concomitantemente. Assim, foram estabelecidas várias estratégias de ensino para grupo, podendo ser destacadas como principais: distribuição dos alunos no espaço de modo a permitir visualização do movimento demonstrado; concomitante demonstração do movimento masculino e do feminino; inclusão de atividades recreativas durante a prática, troca de casais durante a prática oportunizando experimentar diferentes conduções.

O programa de Dança de Salão se consolidou nesta instituição e permanece até hoje graças à dedicação da Profa. Dra. Maristela Moura Silva Lima que deu continuidade. Com minha mudança de instituição em 1987 e encontrando-me com a Profa. Dra. Silvia Deutsch, também com experiência em Dança de Salão, propusemos na instituição superior (UNESP, campos de Rio Claro) a disciplina optativa de Dança de Salão para o curso de formação de professores em Educação Física. Esta também permanece no quadro de disciplinas atual bem como o projeto de Dança de Salão para a comunidade junto às atividades de extensão.

Com o retorno da Profa. Bettina Ried da Alemanha e sua admissão na Escola de Educação Física de Jundiaí tivemos mais uma contribuição em curso de formação de profissionais da Educação Física com a disciplina de Dança de Salão.

Claro que este panorama em termos de formação de profissionais no Brasil é muito limitado, porém é extremamente significativo em termos históricos onde uma modalidade não tradicional passa a ser incorporada por reconhecimento de sua importância e funcionalidade no processo formador.

Coroando a presença da Dança de Salão no Brasil temos hoje a Confederação Brasileira de Dança Esportiva, como Membro da International Dance Sport Federation - IDSF, desde 2005, com sede em São Paulo. Os objetivos principais da Confederação são a divulgação e a formação de professores capazes de ministrar cursos de dança esportiva e inserir o Brasil no contexto mundial da Dança Esportiva (CONFEDERAÇÃO BRASILEIRA DE DANÇA ESPORTIVA, 2008). A Dança Esportiva corresponde à modalidade esportiva e competitiva da Dança de Salão que obedece a regras ditadas pela International Dance Sport Federation e estabelecidas inicialmente no ano de 1930 na Inglaterra_(RIED, 2008). A dança Esportiva é muito divulgada e praticada no continente europeu onde acontece há 100 anos (primeiro campeonato foi em 1907 na França). Estima-se que hoje há 4 milhões de praticantes federados no mundo distribuídos em 84 países, sendo os mais recentes Brasil, Argentina, Chile e México (RIED, 2008).

\section{Conclusão}

Desde a implantação da Dança de Salão no ensino superior no Brasil até hoje, satisfatoriamente assistimos a sua efetivação e proliferação. Também observamos cada vez mais estudos acadêmicos utilizando esta modalidade de dança para entender o ser humano em sua complexidade e singularidade em vários campos do conhecimento. Considerando que a Dança de Salão tem como funções através dos tempos e das culturas o divertimento, a sociabilização, a prática de uma atividade física prazerosa, o culto à beleza, a vertente terapêutica e outras ( $\underline{\text { Volp }}$, 1994), considerando as novas exigências sociais que influenciam a formação dos cidadãos em todos os níveis e as prerrogativas educacionais que o sistema propõe, acredito que este conteúdo pode auxiliar em muitos aspectos e como aglutinador de vários campos de conhecimento. Estou absolutamente ciente que são poucas as instituições de formação acadêmica que integram a Dança de Salão e pouco ainda se trata das intervenções pedagógicas apropriadas deste conteúdo para cada clientela. Mas esta é a abertura de mercado. Este é o momento de adequação do conteúdo aos objetivos educacionais tanto da formação de profissionais quanto da clientela no sistema educacional formal. 
A dança como direito de todo cidadão não deve ficar restrita a apenas um tipo de manifestação. Suas várias linguagens, eruditas e populares, devem conquistar seu lugar na escola, devem preencher a vida, devem continuar seu papel comunicativo, sair do patamar de atividade que alguns consideram como menos nobre reconhecendo que a neurociência, a psicologia, a educação física, a dança, a arte provam sua nobreza. A Dança de Salão é apenas uma destas manifestações, mas aquela com a qual contribuo nesta ocasião.

\section{Referências}

BARBOSA, Ana Mae T. (org.) Arte-educação: leitura no subsolo. São Paulo: Cortez, 1997.

Brasil. Parâmetros Curriculares Nacionais Ensino Médio. Parte II. Linguagens, Códigos e suas Tecnologias. Brasília, Secretaria de Educação Média e Tecnológica, 2000. Disponível em: http://portal.mec.gov.br/seb/arquivos/pdf. Acesso em; 10 ago. 2008.

Brasil. Secretaria de Educação Fundamental. Parâmetros curriculares nacionais:

Arte/Secretaria de Educação Fundamental. Brasília: MEC/SEF, 1997. 130p.

Brasil. Secretaria de Educação Fundamental. Parâmetros curriculares nacionais: Educação Física/Secretaria de Educação Fundamental. Brasília: MEC/SEF, 1997. 96p.

Brasil. Secretaria de Educação Fundamental. Parâmetros curriculares nacionais: Arte /Secretaria de Educação Fundamental. Brasília: MEC/SEF, 1998. 116 p.

Brasil. Secretaria de Educação Fundamental. Parâmetros curriculares nacionais: Educação Física/Secretaria de Educação Fundamental. Brasília: MEC /SEF, 1998. 114 p.

CHARÃO, Cristina. Por instinto, vontade de se comunicar ou por prazer, as razões de dançar estão em um só lugar: o cérebro. Editora Globo: Galileu, jan 2002, p.60-63.

CONFEDERAÇÃO BRASILEIRA DE DANÇA ESPORTIVA - CBDANCE: O que é Dança Esportiva. Disponível em: <www.cbdance.com.br/Oqdancesport.html>. Acesso em: 09 ago. 2008.

daCi Brasil. daCi Brasil . Disponível em http://www.dacibrasil.hpg.ig.com.br/dacipt.htm. Acesso em: 28 out. 2008.
DAMÁSIO, António. O mistério da consciência: do corpo e das emoções ao conhecimento de si. São Paulo: Companhia das Letras, 2000.

KATZ, Helena. Um, dois, três: a dança é o pensamento do corpo. São Paulo, 1994. Tese Doutorado, PUC São Paulo, 1994.

MARQUES, Isabel. Dançando na escola. Motriz, vol.3, n 1, 20-28, 1997.

RIED, B. Dança Esportiva. Apresenta informações sobre Dança de Salão e Dança Esportiva. Disponível em: <www.cdof.com.br/danca7.htm>. Acesso em: 10 ago. 2008.

VOLP, Catia Mary. Vivenciando a dança de salão na escola. São Paulo, 1994. Tese de Doutorado apresentada ao Instituto de Psicologia da Universidade de São Paulo, 1994.

Esse artigo foi apresentado no IV Seminário de Estudos e Pesquisas em Formação Profissional no Campo da Educação Física- NEPEF, realizado na UNESP/Bauru de 20 a 23 de novembro de 2008.

Endereço:

Catia Mary Volp

Av. Dois A, 1165 Vila Bela

Rio Claro SP Brasil

13.506-780

Telefone: (19)3526-4329

e-mail: cmvolp@rc.unesp.br

Recebido em: 30 de setembro de 2008.

Aceito em: 1 de novembro de 2008.

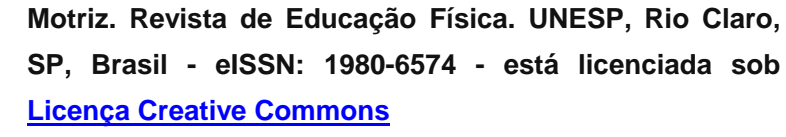

Motriz. Revista de Educação Física. UNESP, Rio Claro, Licença Creative Commons 